to differentiate from acute myocardial ischaemia) and non-specific $\mathrm{T}$ wave changes. ${ }^{6}$ Low ECG voltages suggest a pericardial effusion. ${ }^{10}$ A chest $x$ ray will identify pleuropulmonary disease and allow assessment of cardiac size. An expanding cardiac silhouette on serial chest $x$ rays may indicate a developing effusion. ${ }^{6}$ Two dimensional echocardiography is non-invasive, identifies pericardial effusions, assesses for cardiac tamponade, and acts as a guide for pericardiocentesis.

Untreated pneumococcal pericarditis complicated by septicaemic shock is invariably fatal. Out of hospital asystolic cardiopulmonary arrest also has a poor prognosis, with an overall survival to discharge of about $2 \% .{ }^{112}$ Published reports on the treatment of pneumococcal pericarditis are based upon case reports, small series, and review articles rather than on randomised trials. However, early diagnosis of purulent pneumococcal pericarditis with prompt aggressive treatment significantly reduces mortality. ${ }^{3}$ Cardiac tamponade is not unusual and can occur despite prolonged antibiotic treatment ${ }^{9}$ or even if the site of primary infection has been controlled. In this circumstance, pericardiocentesis is not only diagnostic but life saving too. Effective drainage of the pericardium (and empyema if present ${ }^{313}$ ) in conjunction with high dose intravenous antibiotics offers the best results. ${ }^{3}$ The majority of published reports support open pericardial drainage, arguing that pericardiocentesis alone risks recurrent tamponade. ${ }^{347}$ However, there are isolated case reports of successful outcome from antibiotics accompanied by pericardial catheter drainage with repeated aspiration. ${ }^{1415}$ Some argue that pericardectomy avoids constrictive pericarditis, ${ }^{7813}$ while others regard this as controversial. ${ }^{4}$ The installation of antibiotics within the pericardial sac is unnecessary, as therapeutic levels are achieved with systemic treatment. ${ }^{7}$ General supportive measures are often required to overcome the complications of systemic sepsis and myocardial dysfunction resulting from an associated subepicardial myocarditis. ${ }^{4}$
CONCLUSIONS

Purulent pericarditis is a rare complication of untreated pneumococcal sepsis. It is an acute disease with a fulminant course which often remains undiagnosed during life. The potential for a good outcome depends upon awareness and a high index of suspicion, allowing early diagnosis and aggressive treatment.

1 Woodhead MA, MacFarlane JT, McCracken JS, Rose DS, Finch RG. Prospective study of the aetiology and outcome of pneumonia in the community. Lancet 1987;146:671-4

2 Plouffe JF, Breiman RF, Facklam RR. Bacteraemia with streptococcus pneumoniae: implications for therapy and prevention. JAMA 1996;275:194-8.

3 Kauffman MD, Watanakunakorn C, Phair JP. Purulent pneumococcal pericarditis: a continuing problem in the antibiotic era. Am J Med 1973;54:743-50.

4 Boyle JD, Pearce ML, Guze LB. Purulent pericarditis: review of the literature and report of eleven cases. Medicine $1961 ; 40: 110-44$

5 Klacsmann PG, Bulkley BH, Hutchins GM. The changed spectrum of purulent pericarditis: an 86 year autopsy experience in 200 patients. Am J Med 1973;63:666-73.

6 Berk SL, Rice PA, Reynolds CA, Finland M. Pneumococcal Berk SL, Rice PA, Reynolds CA, Finland M. Pneumococcal
pericarditis: a persisting problem in contemporary diagnosis. Am J Med 1981;70:247-51.

7 Rubin RH, Moellering RC. Clinical, microbiological and therapeutic aspects of purulent pericarditis. Am J Med 1975;59:68-78.

8 Hood RL, Zenker MA. Pneumococcal pericarditis: a rare complication of pneumonia. J Tenn Med Assoc 1995;88: $465-6$.

9 Starling RC, Yu VL, Shillington D, Galgiani J. Pneumococcal pericarditis: diagnostic usefulness of counterimmunoelectrophoresis and computed tomographic scanning. Arch Intern Med 1986;146:1174-6.

10 Guevara RB, Carroll GF, Iteld BJ. Acute non-traumatic cardiac tamponade. J Am Coll Emerg Physicians 1979;8: $270-1$.

11 Herlitz J, Ekstrom L, Wennerblom B, Axelsson A, Bang A, Holmberg S. Predictors of early and late survival after outof-hospital cardiac arrest in which asystole was the firs recorded arrhythmia on scene. Resuscitation 1994;28:27 36.

12 Hamer DW, Gordon MWG, Cusack S, Robertson CE. Survival from cardiac arrest in an accident and emergency department: the impact of out of hospital advisory defibrildepartment: the impact of out of hosp

13 Mabogunje OA, Adesanya CO, Khwaja MS, Lawrie JH, Edington GM. Surgical management of pericarditis in Zaria, Nigeria. Thorax 1981;36:590-5.

14 Kocheril AG, Luttmann C, Sadaniantz A. Pneumococca pericarditis successfully treated with catheter drainage and pertravenous antibiotics. Cathet Cardiovasc Diagn 1991;24: 286-7.

15 Thavendrarajah V, Ghia PS, Kozinn W, Little T. Catheter lavage and drainage of pneumococcal pericarditis. Cathe Cardiovasc Diagn 1993;29:322-4.

\title{
Conversion disorder presenting as a head injury
}

\author{
F E Poyner, P E Pritty
}

\section{Accident and}

Emergency

Department,

Derbyshire Royal

Infirmary, London

Road, Derby DE1 2QY

F E Poyner

P E Pritty

Correspondence to:

Dr F E Poyner, senior

registrar in $\mathrm{A} \& \mathrm{E}$.

Accepted for publication 10 April 1997

\author{
Abstract \\ A case of a conversion disorder which pre- \\ sented as a head injury is described. This \\ is a rare problem and by definition a diag- \\ nosis of exclusion. \\ (F Accid Emerg Med 1997;14:263-264)
}

Keywords: conversion disorder; head injury

Case report

A 35 year old female presented to the accident and emergency (A\&E) department after a car boot lid had fallen onto her occiput. There had been no loss of consciousness. When seen she had an intermittent stutter but there was no detectable neurological abnormality. She was discharged home with an appropriate advice sheet.

Two days later she consulted her general practitioner complaining of an unsteady gait and speech difficulties and was referred directly for a skull $x$ ray. This showed no abnormality but the radiographer was concerned by 
her behaviour and brought her back to the A\&E department for review.

When she was examined at that time there was no external evidence of any head injury and her Glasgow coma scale score was 15 . She had staccato speech, a marked tremor of her left side, a left facial tic, and some left sided weakness. Her gait did not fit any recognised pattern but after only two or three steps she would stagger and collapse. There were no eye signs and at times it was possible to distract her.

She was admitted to the A\&E ward for observation and had computerised tomography of the brain and routine blood tests, none of which showed any abnormality. Over the next two to three days it was noted that her symptoms fluctuated. Because there was some concern that this might be an unusual presentation of demyelination, she also had magnetic resonance imaging of the brain, which was normal.

Further questioning revealed that she had been seen in 1992 for temporomandibular joint pain which was ultimately diagnosed as stress related and responded to antidepressants. She had subsequently discontinued taking them. She had five children and her husband was about to change his job for the third time that year. There were considerable financial worries at home.

Both of her parents had died, one from a cerebrovascular accident and one from a brain tumour, and her brother had died from leukaemia.

When the tests had been completed we explained that we had been unable to identify an organic cause for her symptoms and that we felt her symptoms were stress related. This discussion led to an almost immediate improvement. She was referred for a psychiatric opinion which concurred with ours, and outpatient follow up was arranged.

\section{Discussion}

Conversion disorder is defined as "an alteration or loss of physical function that suggests a physical disorder but is apparently an expression of a psychological conflict or need". ${ }^{1}$ It is a diagnosis of exclusion, rarely reached in an A\&E department. The concept of hysterical conversion is not new-Freud adopted the term "hysterical conversion" in 1894 , but similar terminology was used nearly a century earlier by Ferriar. ${ }^{2}$ More recently hysteria has been a topic of much debate. In a letter to the British fournal of Psychiatry Wiseman ${ }^{3}$ devised a mnemonic as a teaching tool for conversion disorders:

$\mathrm{C}=$ Conscious control lacking

$\mathrm{O}=$ Organic aetiology unproven

$\mathrm{N}=$ Neurological symptoms prevalent

$\mathrm{V}=$ Verisimilitude to physical illness

$\mathrm{E}=$ (a)Etiologically

$\mathrm{R}=$ Related to

$\mathrm{S}=$ Stressor

$\mathrm{I}=$ Indifference may occur

$\mathrm{O}=$ Organic sequelae possible

$\mathrm{N}=$ Not culturally sanctioned.

Engel estimated that between $20 \%$ and $25 \%$ of people will have a conversion disorder at some time in their life, and that the incidence of the disorder on psychiatric wards is between $5 \%$ and $16 \%{ }^{4}$ It is not a diagnosis often reached in A\&E. In an American study of patients with conversion disorder presenting to an emergency department over a 10 year period, 38 out of $42(90 \%)$ had neurological symptoms. There was a high incidence of other illness present, and the majority had a previous psychiatric history. ${ }^{5}$ Folks et al reviewed 62 patients who left hospital with a diagnosis of conversion disorder and found that 18 had a psychiatric disorder and two reported recent head trauma. ${ }^{6}$

It is important to emphasise that there is a myriad of organic diseases which must be excluded before this diagnosis is reached. These include electrolyte disturbances, hypoglycaemia, neoplasms, systemic or occult infections, toxins or poisoning, and demyelination.

\section{CONCLUSION}

Conversion disorder is not a diagnosis often made in A\&E. This case illustrates one way in which it may present and the steps that led to the diagnosis.

1 American Psychiatric Association. Diagnostic and statistical manual of mental disorders, 3rd ed, revised. Washington, DC: American Psychiatric Association, 1987:257-9.

2 Ferriar J. Medical histories and reflections. 1795.

3 Wiseman EJ. Br J Psychiatry 1993;162:272 [letter].

4 Engel GL. Conversion symptoms. In: Macbryde CM, ed. Signs and symptoms: applied pathologic physiology and clinical interpretation, 5th ed. Philadelphia: J B Lippincott, 1970: 650-68.

5 Dula DJ. Emergency department presentation of patients with conversion disorder. Acad Emerg Med 1995;2:120-3. 6 Folks DG, Ford CV, Regan WM. Conversion symptoms in a general hospital. Psychosomatics 1984;25:285-95. 